\title{
Gross revenue risk in Swiss dairy farming
}

\author{
N. El Benni ${ }^{* 1}$ and R. Fingert \\ *Agri-Food and Agri-Environmental Economics Group, Institute for Environmental Decisions, Swiss Federal Institute of Technology, \\ 8092 Zurich, Switzerland \\ †Agricultural Economics and Rural Policy Group, Wageningen University, 6706 KN Wageningen, the Netherlands
}

\begin{abstract}
This study investigated how agricultural policy reforms, including market liberalization and market deregulation, have influenced gross revenue risk of Swiss dairy producers using farm-level panel data between 1990 and 2009. Based on detrended data, variance decomposition was applied to assess how output prices and yields contributed to revenue risk over 3 different periods: the whole period (1990-2009), the first decade (1990-1999), and the second decade (1999-2009). In addition, the effect of expected changes in animal-based support for roughage-consuming cattle and price volatility on revenue risk was evaluated using a simulation model. Prices were the main contributor to revenue risk, even if the importance of yield risk increased over time. Swiss dairy producers can profit from natural hedge but market deregulation and market liberalization have reduced the natural hedge at the farm level. An increase in price volatility would substantially increase revenue risk and would, together with the abandonment of direct payments, reduce the comparative advantage of dairy production for risk-averse decision makers. Depending on other available risk management strategies, price risk management instruments might be a valuable solution for Swiss dairy producers in the future.
\end{abstract}

Key words: revenue risk, dairy farming, variance decomposition, agriculture policy reform

\section{INTRODUCTION}

\section{Motivation and Goals of the Study}

Dairy production involves several risks such as volatile production level and market prices. The US dairy industry, for instance, has experienced a strong increase in price variability due to the reduction in the level of milk price support, an increasing reliance on export markets, and changes in supply and demand (Wolf et al., 2009; Valvekar et al., 2011). For European

Received May 4, 2012.

Accepted October 22, 2012

${ }^{1}$ Corresponding author: elbennin@ethz.ch producers, risk is expected to increase due to market liberalization (Thompson and Gohout, 2000; European Community, 2001; Meuwissen et al., 2003; Sckokai and Moro, 2005). Intensively managed farms (in contrast to pasture-based farms), in particular, may be strongly affected by the price variability of concentrate feed, which can be an important cause of net income risk in dairy farming (Wilson et al., 1987; Schmit et al., 2001).

In addition, milk production may become more risky due to the effect of climate change on fodder yield variability as well as heat stress affecting lactation (Cross, 1994; Kadzere et al., 2002; Chen et al., 2006). Although yield risk is often found to be lower in dairy farming than in crop production (Wolf et al., 2009), strong differences between regions can be observed. For instance, a coefficient of variation for milk yields of $5 \%$ was found for Dutch dairy producers (Meuwissen et al., 1999), which is similar to that found for Swedish producers (4.7\%), but a much higher yield risk was observed for Italian (Tuscany) farmers with a coefficient of variation of 30.3\% (European Community, 2001). Yield levels and yield risk are not only affected by weather conditions but also by the cows' health and farm management. Organic farming, for instance, was found to result in lower and riskier yields than conventional dairy production (e.g., Busato et al., 2000; Trachsel et al., 2000; Sato et al., 2005; McBride and Greene, 2009; Berentsen et al., 2012; D'Antoni and Mishra, 2012).

Empirical studies have found that dairy farmers perceive price risk as one of the most important sources of risk (Martin, 1996; Harwood et al., 1999; Meuwissen et al., 2001; Schaper et al., 2008), and assisting farmers in managing risk is a major concern of agricultural policies in several countries (Bosch and Johnson, 1992; European Community, 2001; Maynard et al., 2005; Tyner et al., 2005). To tailor this assistance to the needs of farmers, it is necessary to quantify how different drivers contribute to revenue risk. Although market liberalization can lead to an increase in price variability for domestic producers, the role of direct payments in farmers' incomes is very important in risk considerations. Because direct payments are a stable, and thus a risk-free, source of income, farm revenues are less variable (Cafiero et al., 2007; Agrosynergie, 2011; 
El Benni et al., 2012). Thus, the effects of direct payments as well as the effects of increasing price volatility need to be taken into account if risks are estimated and future developments are discussed. Furthermore, the allocation of direct payments can affect the comparative risk position of specific farm activities. If, for instance, direct payments are tied to a certain farm activity such as dairy production, this improves the position of this activity in a whole farm portfolio in terms of risk.

The goal of this study was to assess how gross revenue risk in Swiss dairy production has changed over time and might change in the future. The effects of past and proposed policy changes on dairy farmers are of particular importance for Swiss policy makers as grasslandbased dairy and cattle farming contribute 40 to $50 \%$ to the gross agricultural income in Switzerland. The high contribution of roughage-based livestock production to Swiss agriculture is caused by the natural production conditions (permanent grassland and productive alpine pastures cover $72 \%$ of the cultural land; Bötsch, 2004; Jeangros and Thomet, 2004). Furthermore, Switzerland serves as an interesting case study for other countries, as the market and policy environment of farmers has changed considerably over the last 2 decades. From the early 1990s onward, Swiss agricultural policy emphasized the liberalization of the milk market by reducing market price supports and, after a transition period, abolished the milk quota system in 2009. Direct payments based on roughage animal units will be abandoned with the next policy cycle. These developments are expected to affect the gross revenue risk in Swiss dairy production, as well as the riskiness of dairy production compared with other farm activities.

To assess the effects of past and proposed policy changes on revenue risk in Swiss dairy production, we use farm-level panel data of 412 milk-producing farms for the period from 1990 to 2009. Based on detrended data, we first estimated production, price, and revenue risks for each single farm using the coefficient of variation. Second, we applied a variance decomposition procedure to specify if production or price risk was the most important source of gross revenue risk. The analyses were carried out for different periods to test whether the contribution of prices and yields to revenue risk changed with past policy changes. Third, we simulated how changing levels of direct payments and price volatilities would affect farmers' revenue risk using stochastic simulation. This study is the first empirical investigation into the perils faced by Swiss dairy farmers and shows how price, yield, and revenue risk have changed over time. The results indicate the potential of possible risk management instruments in dairy production, which depends, in part, on the extent of risk coming from yields and prices.

\section{Policy and Market Environment of Swiss Dairy Producers}

Over the last 2 decades, Swiss agricultural policy introduced various measures to deregulate and liberalize the market. At the same time, more weight was put on decoupled direct payments to (besides internalizing negative effects from agriculture) support the income of farmers. From the early 1990s onward, prices of agricultural outputs decreased due to modifications in the border protection schemes and the abolishment of price and sales guarantees (see e.g., BLW, 2007; El Benni and Lehmann, 2010). Furthermore, starting in 2002 with tariff reductions and the removal of technical barriers to trade, a bilateral trade agreement with the European Union (EU) came into force in 2007 that totally liberalized the market for cheese between both trading partners (Jörin et al., 2006). Since then, no border protection is provided for the "yellow line" (cheese) but producers are compensated by an amount of 0.15 Swiss francs $(\mathbf{C H F}$, where US $\$ 1=0.93 \mathrm{CHF})$ per $\mathrm{kg}$ of raw milk that is processed into cheese and by $0.03 \mathrm{CHF}$ per $\mathrm{kg}$ if the milk is produced without silage feeding. These support payments were introduced in 2000 and were steadily reduced over time. They are given to the cheese processors who pay higher milk prices to the producers. Thus, for milk delivered to cheese dairies, a $10 \%$ price premium is common (Mann and Gairing, 2011). In contrast, the "white line" (e.g., that includes milk powder, butter, and yogurt) still receives support from border protection schemes but all export refunds and internal subsidies (such as butter used in industry) were abolished by 2009 and the financial means were partly transferred into decoupled direct payments (Chavaz, 2010).

An exceptional step - in the European context-toward market deregulation was the decision of the Swiss Parliament in 2003 to abolish the milk quota system in 2009 to allow for a flexible and market-driven supply allocation and to strengthen the competitiveness of milk production (Chavaz, 2010). From 2000 onward, Swiss farmers could trade their individual milk quotas (FOAG, 2000). In a transition period from 2006 to 2009, farmers could transfer their milk quota to a global quota by becoming a member of a milk producer organization (PO) or milk processor organization (PPO). By joining a PO or PPO, milk producers are required to complete a 1-yr (at least) contract that stipulates the quantity and price of milk sales. Although the contracted quantity often matches the amount of the former (individual) quota, the law does not specify whether amount and price must be fixed for $1 \mathrm{yr}$. In practice, almost $50 \%$ of milk buyers have not determined the amount of time for which a price is fixed, but 
can change it whenever it appears necessary (Mann and Gairing, 2011). Furthermore, the pricing system can differ dependent on the PO or PPO to which the milk is delivered. For instance, some organizations apply "A" and "B" (lower) prices, respectively, for production inside and outside the former (i.e., individual) quota. The prices for production outside of the former quota (i.e., the $\mathrm{B}$ prices) are often linked to the $\mathrm{EU}$ milk price. Others operate with A and B quantities by purchasing an average of $80 \%$ as A-price milk and $20 \%$ as B-price milk and some do not officially operate with the A and $\mathrm{B}$ pricing system but apply heavy price reductions if the producer exceeds his contracted volume (Mann and Gairing, 2011). In May 2009, all global and individual milk quotas expired. However, the requirement of contracts between producers and milk purchasers remain in force until 2015 (Chavaz, 2010).

To compensate Swiss farmers for foregone market profits due to market liberalization measures but also for environmental reasons, direct payments (DP) were introduced in 1992 and were based on cross-compliance obligations in 1999 (for more detail on the DP system, see Mann, 2003; El Benni and Lehmann, 2010; El Benni et al., 2012). Since then, farmers have had to follow the guidelines of integrated production to be eligible for DP, which is currently the case for 90 to $95 \%$ of the dairy farms in Switzerland (Roesch et al., 2006). The current DP system distinguishes between general and ecological (including animal welfare payments) DP that are directly or indirectly linked to the farm area. For Swiss dairy farmers, this implies that they receive general DP per hectare of farm land (area-based DP) and per roughage animal unit (animal-based DP). Furthermore, farmers producing under adverse production conditions in the hilly and mountainous regions receive an additional amount of area- and animal-based DP. To be eligible for governmental support, the number of roughage animal units allowed is restricted in the crosscompliance obligations and depends on the natural factor endowment and thus differs by region. For instance, a farmer located in the valley region is allowed to have 2.0 roughage animal units (equivalent to 2 milk cows) per hectare of grassland. These boundaries are set to reduce the negative externalities from agricultural production. Roughage animal-based payments were 200 CHF per milk cow in 2007 and 2008, and 450 CHF per milk cow since 2009. However, the current DP system with its promotion of roughage animal units has led, at least to a certain extent, to intensification in milk and meat production (Stöcklin et al., 2007). Furthermore, animal-based payments are not in compliance with the regulations of the World Trade Organization. To increase the effectiveness and efficiency of the DP system, Swiss policy makers are currently working on a proposal for a new DP system that (among others) foresees the abolishment of animal-based payments (see e.g., Lanz et al., 2010). All DP will then be based on farm area. Model calculations on the effects of this new policy scheme showed that Swiss farmers will not receive smaller DP in total (Mann et al., 2012). Nevertheless, income risk for dairy producers will change in terms of gross revenues per milk cow and will affect the riskiness of dairy production compared with other farm activities.

\section{MATERIALS AND METHODS}

\section{Measuring Price, Production, and Revenue Risk}

The first objective of this paper was to investigate price, production, and gross revenue risk of Swiss dairy producers from 1990 to 2009. As described in the previous section, the change from market support to decoupled DP has led to decreasing prices, and DP requirements as well as adjusted incentive schemes have changed the production intensities and therefore yield levels in Swiss agriculture (Schläpfer et al., 2002; Finger, 2010a). Furthermore, technological improvements; for example, in terms of advanced breeding techniques and optimization in management, have led to increasing yields over time (Bapst, 2001). Thus, both price and yield levels are expected to have changed during the period considered. To avoid an overestimation of price and production risks, these trends in the time series must be removed.

To ensure an appropriate capturing of deterministic developments over time, we first estimated the development of prices (in $\mathrm{CHF} / \mathrm{kg}$ ) and yields (measured on a per-cow basis, i.e., in $\mathrm{kg} / \mathrm{cow}$ ) using kernel density estimation. This nonparametric approach does not require prior assumptions on the relationship between the predictors and the response variables. In contrast, the regression function is estimated nonparametrically directly from the data. Based on the results of the kernel density estimation, we choose the appropriate parametric function to detrend the price and yield data in a second step. Hence, the choice of the parametric function is based on a data-driven approach that depicts the true development of the data over time and thus reveals a possible trend as well as deviations from this trend without introducing estimation biases due to imperfect choices of a parametric model.

The conditional density estimations using kernels were derived as follows: In the case of a bivariate setting with continuous data, let $Y$ be the dependent variable and $X$ the covariate; that is, the explanatory variable. The marginal density of $X$ is $f(x)$ and the joint density of $(Y, X)$ is $f(y, x)$. The conditional density estimate 
$f(x \mid y)$ is then defined as the ratio between the joint and the marginal density:

$$
f(y \mid x)=\frac{f(y, x)}{f(x)}=\frac{\sum_{i=1}^{n} K_{h 2}\left(x-X_{i}\right) K_{h 1}\left(y-Y_{i}\right)}{\sum_{i=1}^{n} K_{h 2}\left(x-X_{i}\right)},
$$

where $K$ defines the kernel function, $h$ is the bandwidth, $n$ is the number of observations, $X_{i}$ and $Y_{i}$ are the predictors and the explanatory variable, respectively, and $x$ and $y$ are the focal points (the $x$ - and $y$-values at which $f(y \mid x)$ is to be estimated). The kernel $K$ is a smoothing function that defines how data within a given range (neighboring cells) around the focal point $x$ are weighted. We choose the Gaussian kernel as smoothing function that gives normally distributed weights to the data; that is, values near the focal point are weighted higher than values far away from the focal point and this weighting function follows a normal distribution. The bandwidth $h$ is the smoothing parameter that defines the range (neighboring cells) over which data are used to calculate the conditional density estimates. We use least square cross-validation, which is a datadriven approach based on the principle of selecting a bandwidth that minimizes the integrated mean squared error of the resulting estimates ( $\mathrm{Li}$ and Racine, 2007).

The development of the prices and yields over time derived by kernel density estimation were plotted and taken as basis for the choice of the parametric model that fit the data best. We use the MM-estimator, a robust regression technique with a superior performance in presence of outliers, to extract the trend from the data (Finger, 2010b). The trend estimation was based on the aggregated data set that comprised all farms. The parameters derived at this aggregated level were then used to detrend the price and yield data for each single farm.

Price and yield risk were measured at the farm-level (i.e., for each farm), using the coefficient of variation as a measure of the relative variability of yields and prices. More precisely, from the detrended data, the mean $\mu$ and standard deviation $\sigma$ over a period $t$ per farm $i$ were estimated and used to construct the coefficient of variation $C V_{i t}=\sigma_{i t} / \mu_{i t}$. In addition, we estimated $\mathrm{CV}$ for gross revenues, which were derived by multiplying the detrended yield and price data at the farm level.

\section{Decomposing Revenue Risk}

The second objective of this paper was to determine the sources of revenue risk. Thereby, we focused on gross revenues that were defined as the product from prices (in CHF per $\mathrm{kg}$ of milk) and yields ( $\mathrm{kg}$ of milk per cow and year) and were calculated on a per-cow basis. We have chosen to work on a per-cow basis in contrast to a whole farm-level analysis because this enables us to identify changes in price and yield risks explicitly. Furthermore, this level of analysis is capable to indicate changes in the-ceteris paribus - comparative risk position of dairy production. For instance, a risk-averse decision maker not only bases his or her decision on mean revenues but also on the variance in revenues, which is affected by the development of price and yield risk as well as the correlation between prices and yields. Increasing risk in dairy production can, $c e-$ teris paribus, reduce the comparative advantage of this production type and thus affect structural change in Swiss agriculture.

Applying the Taylor series expansion about the means of prices and yields, expected revenues, E(rev), can be written as follows (Burt and Finley, 1968):

$$
E(\text { rev })=\mu_{p} \mu_{q}+\operatorname{cov}(p, q),
$$

with $\mu$ denoting the means of prices $p$ and yields $q$, respectively, and $\operatorname{cov}(\cdot)$ being the covariance between both variables.

To quantify the contribution of prices and yields to revenue variability, we used the variance decomposition method proposed by Goodman (1960) and Bohrnstedt and Goldberger (1969) (see Schmit et al., 2001 for an application in agriculture). More precisely, we decomposed the observed variability of revenues $\operatorname{var}(r e v)$ for a single farm household into the variability coming from prices, $\operatorname{var}(p)$, and the variability coming from yields, $\operatorname{var}(q)$ :

$$
\operatorname{var}(\text { rev })=\mu_{q}^{2} \operatorname{var}(p)+\mu_{p}^{2} \operatorname{var}(q)+2 \mu_{p} \mu_{q} \operatorname{cov}(p, q) . \quad[3]
$$

Assuming normally distributed prices and yields, the first 2 terms of equation [3] are the direct effects of prices and yields, and the third term is a first-order interaction effect between both variables. If prices, yields, or both are not normally distributed, then equation [3] is only an approximation of the variance of gross revenues. Hence, the error introduced depends on the degree of nonnormality and the magnitude of price and yield variance (Perry et al., 1989). To test if the approximation presented above is sufficient to represent revenue risk, we used Wilcoxon rank sum tests and Ansari Bradley tests to compare the mean and variances of the estimates derived from this procedure with the observed revenue variability.

To quantify the direct and indirect contribution of prices and yields to revenue risk, we normalized the 
direct and first-order interaction effects by dividing the corresponding terms of equation [3] by the sum of the direct effects as proposed by Burt and Finley (1968). Thus, the direct effects of prices and yields sum to unity, and an increasing variance of either component increases net revenue variability. Furthermore, a negative (positive) covariance shows that prices and yields move in the opposite (same) direction over time. Hence, a negative covariance effect would show that low yield events are accompanied by high prices, and revenue variability is thus reduced. This so-called natural hedge would, for instance, reduce the need for risk management instruments such as revenue insurance.

To distinguish between the different policy reform steps; namely, the effect of the first agricultural reform in 1992 and the second reform in 1999, the analyses were conducted not only for the whole period (1990 to 2009) but also for 2 different periods. The first period covered the years 1990 to 1999 and the second period covered the years 1999 to 2009.

\section{Evaluating Future Revenue Risk Under Different Price and DP Conditions}

The effects of potential changes in the level of animalbased DP, as well as in price variability on revenue risk, are simulated in sensitivity analysis. More precisely, the average results over all farms from the previous analysis are used as input for the simulations. Thus, the effects of changing direct payments and changing price risk are illustrated for an average dairy farm in Switzerland. Sensitivity analyses (representing potential changes in near future) are based on yield and price distributions derived for the most recent period in our sample (i.e., 1999 to 2009).

Our sensitivity analyses comprised a range of DP from 0 to $900 \mathrm{CHF}$, depicting the current situation of $450 \mathrm{CHF} /$ cow, a doubling of this DP, as well as the recently proposed abolishment of these payments. Because our analysis focused on a per-cow basis as reference level to investigate gross revenue risks, other DP that are independent from dairy production (e.g., general area-based DP) are not considered. Although these payments can affect income risks at the wholefarm level (El Benni et al., 2012), we were focused on the relative risk position of dairy production and the gross revenue risk arising specifically in this production activity.

We considered CV of milk prices ranging from the current situation to a 3 -fold increase, representing potential increases in price variability caused by further market liberalization (van Winsen et al., 2011; Yonkers, 2011). To simulate expected CV of revenues, we used equation [3] and the level of the expected revenue, which depends on expected prices and yield as well on the level of DP. Simulation results are presented using contour plots.

Although changes in price variability affect only farmers' risk, changes in the level of direct payments also change expected revenues. To integrate both effects from the perspective of a risk-averse farmer, we integrated expected revenue and revenue variance into a utility framework. More specifically, we follow Di Falco and Chavas (2006) and expressed farmers' utility in certainty equivalents $(\mathbf{C E})$ that denote the nonrandom level of payoff that is rated (in terms of utility) equivalent to an uncertain (i.e., random) level of payoff. The $\mathrm{CE}$ is defined as $\mathrm{E}(\mathrm{rev})$ minus the risk premium $(\mathbf{R P})$ :

$$
C E=E(r e v)-R P .
$$

The RP represents the costs of risk in monetary terms; that is, the amount of money the decision maker is willing to pay to eliminate exposure to risk. Following Pratt (1964), we approximated the RP as follows:

$$
R P \approx 0.5 \gamma \frac{\operatorname{var}(r e v)}{E(r e v)},
$$

with $\gamma$ being the coefficient of relative risk aversion. As shown in equation [5], we assumed that the RP is higher (i.e., risk plays a more important role in decision making) if the expected revenue is small. This assumption was based on the observation that decision makers are more vulnerable to income variability if their income levels are already small. We presented both CE and RP for our sensitivity analyses described above, assuming a moderate risk aversion with $\gamma=2$ (for overviews, see Di Falco and Chavas, 2006; Gardebroek, 2006).

\section{Data}

We use annual farm-level records of the Swiss farm accountancy network (FADN) that include prices (CHF/ $\mathrm{kg}$ of milk) and yields (kg/cow) over the period 1990 to 2009. We focused on gross revenue risk, which comprises price and yield risk. Costs were not considered a source of risk in our analyses because of limited data availability; for example, fodder costs on concentrated feed and roughage are not available on a per-cow basis. However, as Swiss dairy production is highly pasture-based, we expected fodder costs on concentrated feed to be less important for Swiss producers compared with other countries (see e.g., Wilson et al., 1987; Schmit et al., 2001 for the United States). Clearly, roughage production is also variable (e.g., Finger et al., 2010) because it is affected by weather conditions and therefore may 
contribute to revenue risk in dairy farming. However, the interactions between on-farm roughage production, purchased roughage, and concentrate use cannot be calculated with the underlying data. Furthermore, the estimation from FADN data of energy units required at the cow level, which depends on milk production and maintenance requirements of dairy cows, is outside the scope of this study (for a method to include fodder costs, see Berentsen and Tiessink, 2003; Berentsen et al., 2012). However, we expected that some of the risks coming from roughage production (e.g., those due to variable quality levels; Finger et al., 2010) were implicitly reflected in the variability of milk yields.

Milk prices are deflated by the consumer price index with base in 2010. To ensure that farms included in our sample operated under similar production conditions, we limited our analysis to nonorganic farms located in the valley region (i.e., farms in the hill and mountain regions were excluded) having milk production as the primary activity. Finally, we selected farms that had data records for at least $15 \mathrm{yr}$ within the period from 1990 to 2009 to allow for sufficient risk analysis for each farm. These criteria led to 7,157 observations from a sample of 412 farms.

\section{RESULTS AND DISCUSSION}

\section{Price, Production, and Revenue Risk of Swiss Dairy Producers}

First, we used nonparametric kernel density estimation to identify price and yield developments over time. This estimation was conducted over the whole data set (i.e., all farms), and the results are shown together with bootstrap confidence intervals (derived from 199 bootstrap samples) in Figure 1. Figure 1 shows that yields increased between 1990 and 2009. In contrast, prices decreased strongly from 1990 until the end of the 1990s but became stable thereafter with a peak in 2008 and a strong price decline in 2009. The price development of the last years considered can be explained by the fact that about $90 \%$ of dairy farmers had joined a PO or PPO, which were, unlike individual producers, able to apply to the Federal Ministry for additional production licenses. As a consequence of requested additional milk volumes (which exceeded the historical milk quota by $3 \%$ ) and the decline in world market prices in the second half of 2008, national milk prices fell dramatically in 2009 (Chavaz, 2010; Mann and Gairing, 2011). Figure 1b clearly shows the effect of policy reforms on prices. To account for these changes, we considered not only the whole time period (1990-2009) in our subsequent analyses but also split the data set into periods from 1990 to 1999 and from 1999 to 2009.
Supported by the information derived from the kernel density estimates, quadratic models over all farms were estimated for yields and prices. The estimated trends (i.e., parameters) derived from the aggregated level (i.e., over all farms) were then used to detrend prices and yields at the farm level. By multiplying the detrended price and yield data, revenues were derived for each single farm. Then, for each farm, the CV were calculated for prices, yields, and revenues, once for the whole period (1990-2009) and then for the first (1990-1999) and second (1999-2009) decades. The results for the CV for prices, yields, and revenues for these 3 periods are shown in Figure 2.

Figure $2 \mathrm{a}$ and $\mathrm{b}$ and Wilcoxon rank sum tests showed that the $\mathrm{CV}$ of prices were significantly higher than those for yields over the whole period as well as for the first and second periods considered. For instance, between 1990 and 2009, the median of the CV for prices was 0.10 and that for yields was 0.08 . This high importance of price risk compared with yield risk in dairy production is in line with results from other studies (Wolf et al., 2009). Furthermore, the Wilcoxon rank sum tests showed that the CV for prices and yields and subsequently revenues (see Figure 2c) significantly increased from the first to the second period. The increase in yield risk could be a result of different factors, including climate change affecting roughage production and therefore yield risk, or heat stress affecting lactation, or changes in genotypes. Furthermore, an increase in yields as observed in Swiss dairy production is often accompanied by an increase in variance (Costa, 1999). Price risk increases are a result of market deregulation and market liberalization. However, even if revenue risk increased over time, the CV for gross revenues of 0.09 (1990-1999) to 0.12 (1999-2009) were low compared with those of other countries (see e.g., Wolf et al., 2006 for gross revenue risk of dairy production in the United States) and low compared with the variability often measured in crop production. For instance, CV for gross revenues of crops in Switzerland were found to range between 0.16 (for wheat) and 0.29 (for rapeseed; El Benni and Finger, 2012).

\section{Decomposition Results}

As described in equation [3], revenue risk (i.e., the variance in revenues) for each farm was decomposed into risk coming from yields and risk coming from prices. Note that results refer to revenue variability measured at the per-cow level throughout the paper. Furthermore, the interaction effects between yields and prices for each farm were estimated. A negative priceyield correlation shows that prices and yields move in the opposite direction, which means that an increase 
a) kernel density estimates of prices

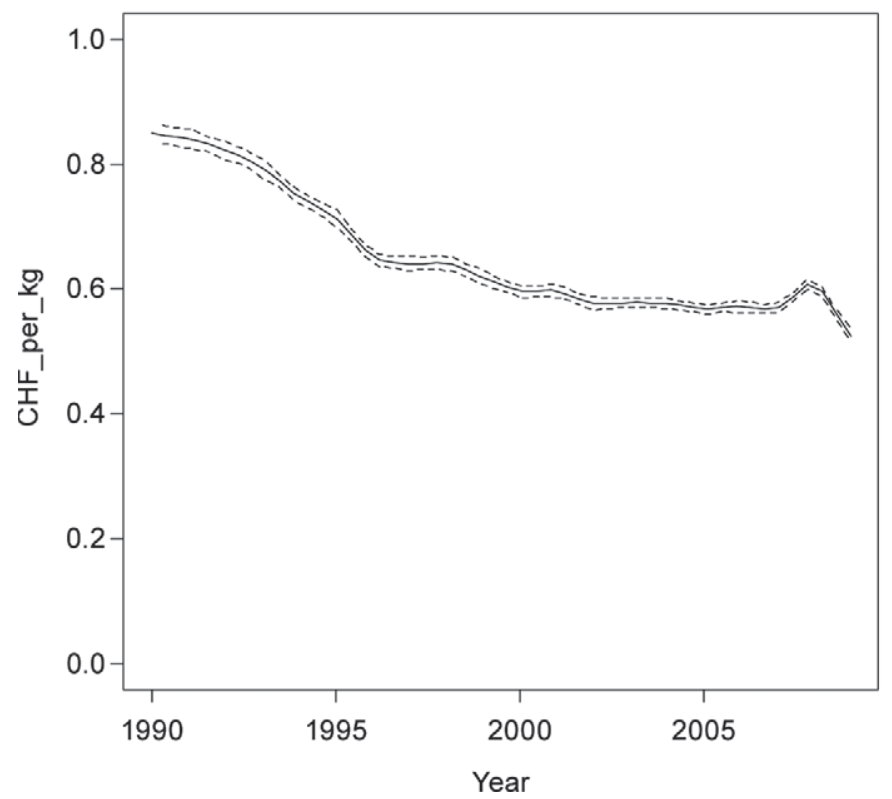

b) kernel density estimates of yields

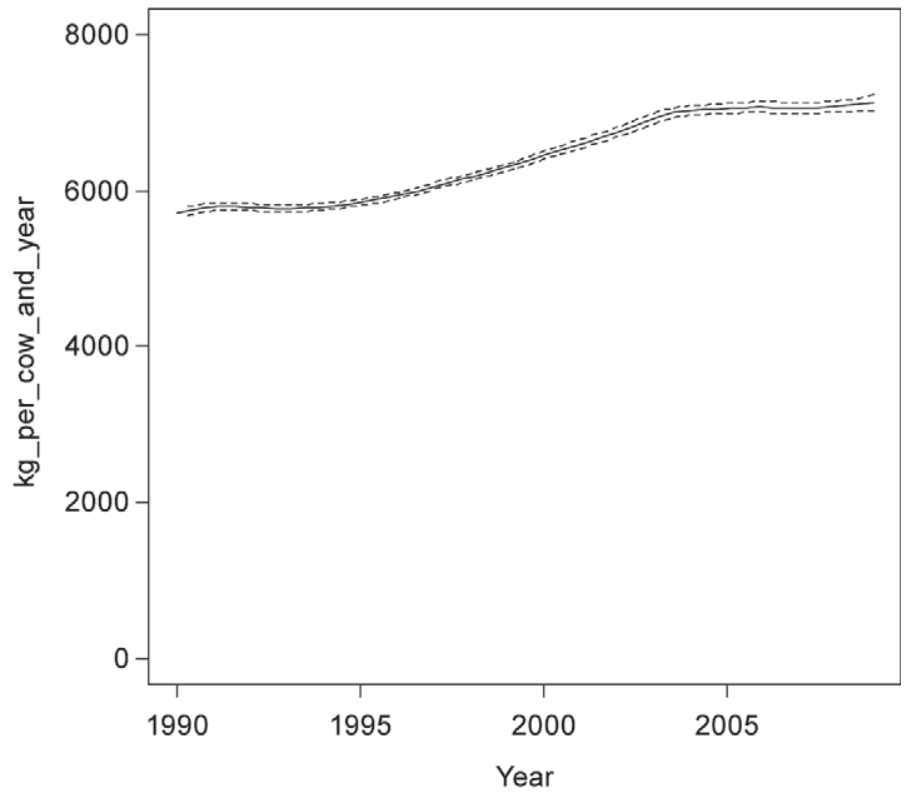

Figure 1. Kernel density estimation results for price (Swiss francs, CHF, per kg) and yield (kg per cow and year) developments between 1990 and 2009. Dotted lines represent bootstrapped $95 \%$ confidence intervals.

in yields leads to lower prices and vice versa. Such a negative correlation between prices and yields (i.e., the natural hedge) reduces revenue risk. Wilcoxon sum rank tests and Ansari Bradley tests indicated no significant difference of the means and variances between the approximated gross revenue variance (based on equation [3]) and the observed (i.e., observations based on detrended revenues) revenue variance at the $10 \%$ level.

Figure 3 depicts the distribution of the standardized variance decomposition results. Supporting the results derived from the $\mathrm{CV}$ above, Wilcoxon rank sum tests showed that yield risk was significantly less important than price risk. For instance, the variance in prices made up $66 \%$ of the variance in revenues over the period from 1990 to 1999 (note that the median values over all farms are reported within the text). However, the importance of price risk decreased over time, with price variability contributing only about $62 \%$ to revenue risk between 1999 and 2009. Along these lines, yield risk made up only $34 \%$ of total revenue variance in the first period and $38 \%$ in the second period. Wilcoxon sum rank tests showed that the increase in the direct yield effects and the decrease in direct price effects from period 1 (1990-1999) to period 2 (1999-2009) were significant at the $5 \%$ level.

The indirect price-yield effects (i.e., the standardized covariance between prices and yields) were negative for most Swiss dairy producers, and showed (on average) a significant natural hedge at the farm level. However, the Wilcoxon rank sum tests showed that the negative covariance between prices and yields significantly decreased from (a standardized) coefficient of -0.23 to -0.14 from the first to the second period. This development is likely the result of 2 factors: First, decreases in the natural hedge occur because of the integration of the Swiss market into the European market due to the bilateral trade agreement for cheese (see e.g., FMFACP, 2011). Second, in the first period considered (1990 to 1999), milk quotas were fixed at the farm level and an increase in yield beyond the quota volume led to price decreases. Since 2000, however, individual milk quotas became tradable. Furthermore, in 2006, most farmers transferred their individual quota to a PO or PPO. These developments led to a less strong negative correlation between prices and yields. The natural hedge is, therefore, in our case, also policy driven and is not solely coming from the market environment.

Based on the $\mathrm{CV}$ for revenues, we categorized all farmers of the sample into 4 risk groups: the first group comprised those $25 \%$ of farmers with the lowest CV of revenues (i.e., revenue risk) and the fourth group comprised those $25 \%$ of farmers with the highest CV of revenues. Again, this categorization was done for the whole period 1990 to 2009 as well as for 1990 to 1999 and 1999 to 2009.

Table 1 show the CV for revenues, prices, and yields on average over all farms (see last column) and for each of the 4 risk groups (i.e., quartiles of the distribution 
a) yield risk

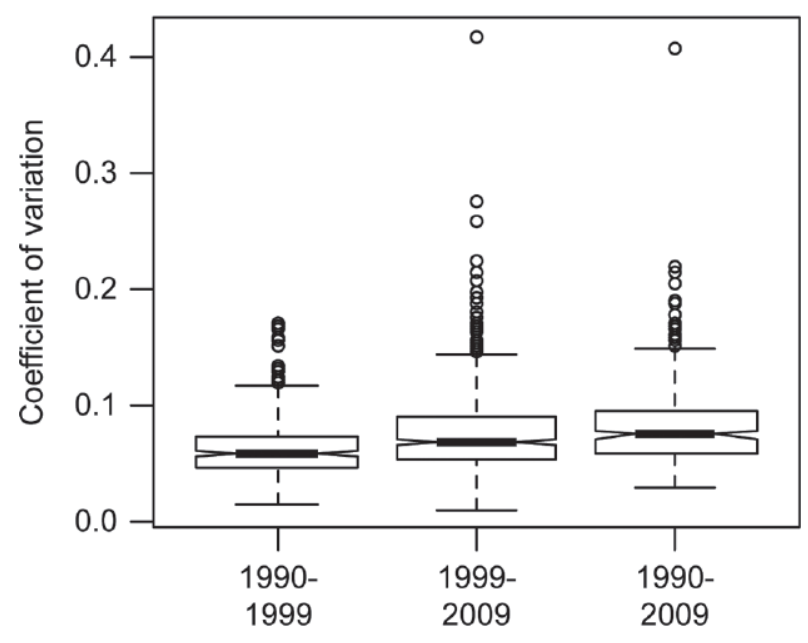

b) price risk

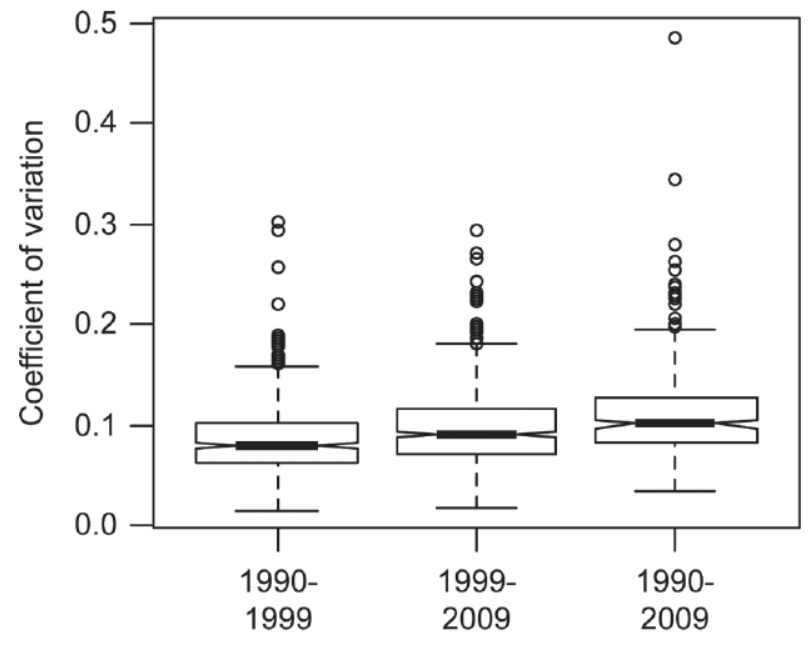

c) revenue risk

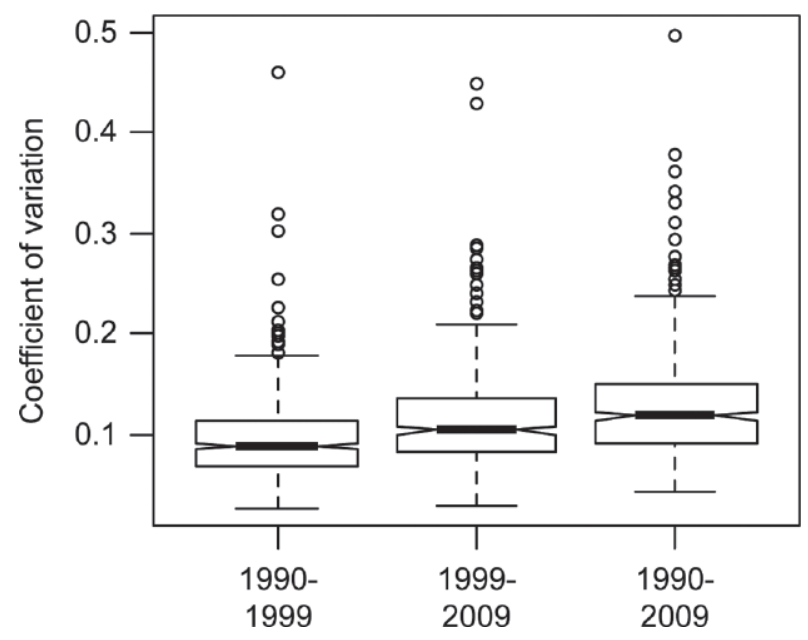

Figure 2. Farm-level price, yield, and revenue risk (CV) over different periods. of the $\mathrm{CV}$ of revenues). All values presented are the medians of the respective distribution. For the period 1990-2009, price as well as yield risk increased with an increase in revenue risk. The results derived by the variance decomposition method (presented below the CV in Table 1) show that a high CV of revenues coincided with a high importance of price risk. For instance, over the whole period considered (i.e., 1990 to 2009), prices contributed $59 \%$ to revenue variability for farmers in the lowest risk group (i.e., farmers with the lowest $\mathrm{CV}$ for revenues) and $70 \%$ for farmers in the highest risk group. Furthermore, we found that farmers with lower revenue risk faced a much stronger natural hedge (i.e., negative price-yield correlation) than did farmers in the high-risk groups (Table 1). This was supported by the Wilcoxon rank sum tests that showed significant decreases of the negative price-yield correlation with an increase in revenue risk. For the highest risk group, a positive correlation between prices and yields was observed

However, a more precise picture was apparent when the first period (1990-1999) was compared with the second period (1999-2009). First, the difference in the $\mathrm{CV}$ of revenues between the risk groups was much higher in the first compared with the second period. Hence, revenue risks became more equally distributed across farms. The same development was observed for the CV of prices and yields, which became similar between the different risk groups. This is also underlined by the variance decomposition results. We found that for the first period, price risk was much more important in high-risk groups compared with low-risk groups. In contrast, the importance of price and yield risk did not follow a clear trend with regard to revenue risk in the second period. In addition, no significant difference between revenue risk groups with regard to the natural hedge was observed between the risk groups for the period 1999-2009. In contrast, significant differences across risk groups with respect to price-yield correlations were found for the first period. Even though price risk became slightly less important over time (see the decomposition results between the 2 periods in the last column of Table 1), Wilcoxon rank sum tests showed that the $\mathrm{CV}$ of prices were still significantly higher than the CV for yields.

\section{Effects of Changes in DP and Price Risk on Revenue Variability}

Finally, a simulation study was conducted to evaluate the effects of changing DP and possible increases in price risk. Price and yield distributions as well as the covariance between both variables used for the simulations were taken from the previous analyses, using the 
a) direct and indirect effects 1990-1999

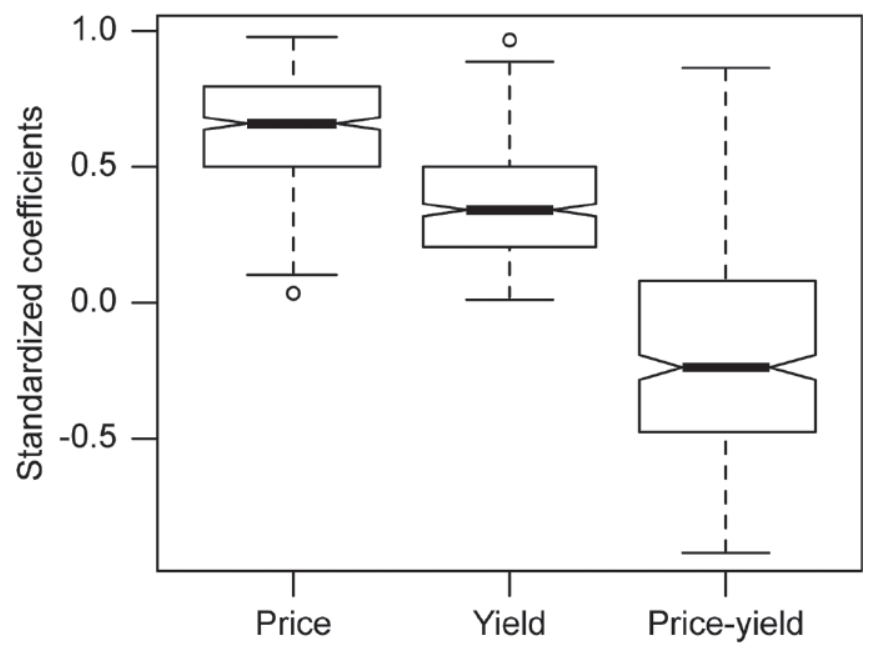

b) direct and indirect effects 1999-2009

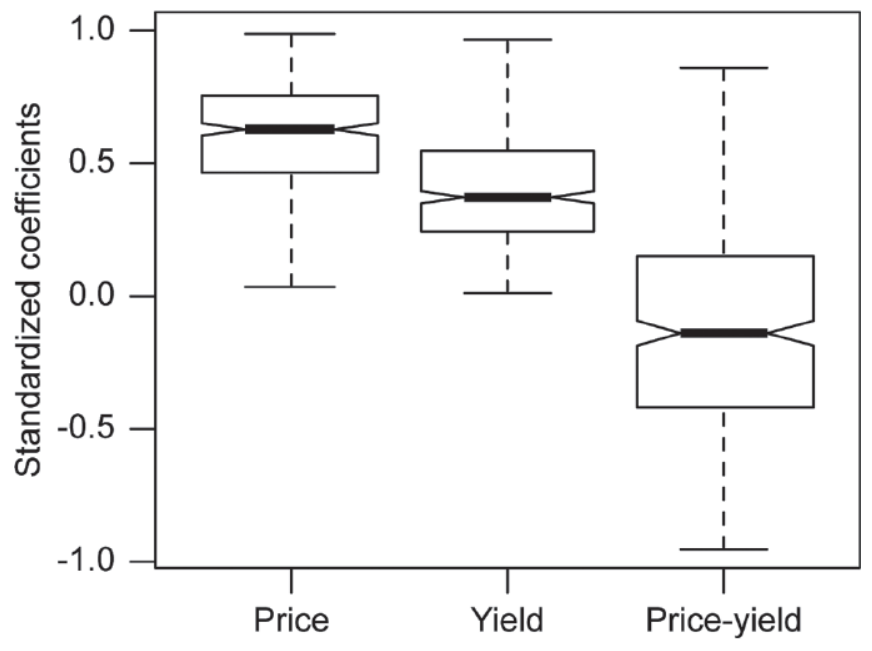

c) direct and indirect effects $1990-2009$

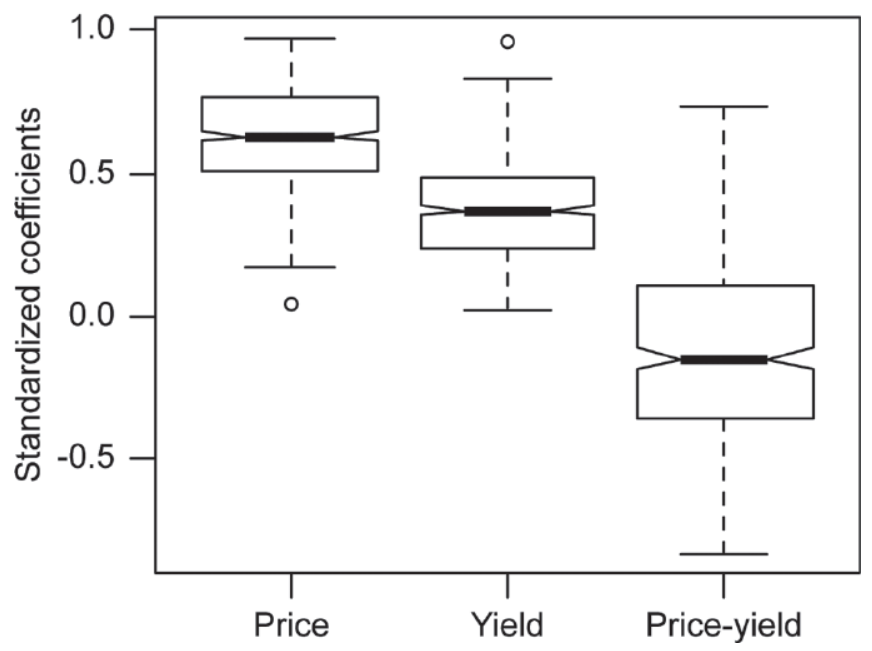

Figure 3. Variance decomposition results. period from 1999 to 2009. The mean and standard deviation of milk prices were 0.5778 and $0.0516 \mathrm{CHF} / \mathrm{kg}$, respectively. Average milk production was $6,916 \mathrm{~kg} /$ cow with a standard deviation of $466.71 \mathrm{~kg} / \mathrm{cow}$. The correlation between farm-level milk production and milk price was -0.1468 . Sensitivity analyses comprised direct payments from 0 to $900 \mathrm{CHF}$, and CV of milk prices ranged from 0.10 to 0.30 . Figure 4 shows the $\mathrm{CV}$ of revenues resulting from these simulations. Again, it is important to highlight that these results refer to gross revenue risks on a per-cow basis.

Figure 4 shows that increases in price variability would lead to substantial increases of revenue variability. For instance, going from the initial situation (black dot in Figure 4) to a milk price CV of 0.30 would increase the revenue $\mathrm{CV}$ from about 0.10 to 0.28 . Furthermore, Figure 4 shows that DP can reduce revenue variability as they provide a risk-free income source and, ceteris paribus, increase revenues. However, in the case considered here, their risk mitigation potential is limited. This is because the amount of DP is small compared with the level of gross revenues, and its influence on the mean and variance of revenues is thus limited. Even the doubling of roughage animal-based DP can only outweigh (i.e., ensure no increase in relative revenue risk) increases of the milk price $\mathrm{CV}$ to about 0.12 . The small influence of DP on revenue risk also implies that the abolishment of DP under current price risk would only increase relative revenue variability to about 0.12 . In summary, animal-based DP provided by governments cannot fully serve as a risk mitigation measure at the unit scale (i.e., at the cow level). Nevertheless, the abandonment of animal-based DP affects the comparative advantage of milk production as revenues per milk cow decrease and revenue risk increases. This will affect management decisions of risk-averse farmers. This analysis suggests that market-based risk management instruments might be a valuable solution for Swiss dairy producers to cope with potential price risk increases in the future. Of course, the use of market-based risk management instruments for Swiss milk producers also depends on other available instruments to cope with price risk. For instance, forward contracts with processor organizations can be used to control for milk price risk, and whole-farm strategies (e.g., diversification) can alleviate the effect of milk price volatility.

Figure 5 shows the $\mathrm{CE}$ resulting for different combinations of direct payments and price variability. By definition, DP increase and price variability decrease CE. For instance, if the price variability increases to 0.30 , the farmer would have to be compensated with an additional 260 CHF per cow and year to stay at the same CE level as with a milk price $\mathrm{CV}$ of 0.10 (following the iso-CE line through the initial situa- 
Table 1. Price, yield, and revenue risk and variance decomposition results from 1990-2009 (medians of the respective distribution)

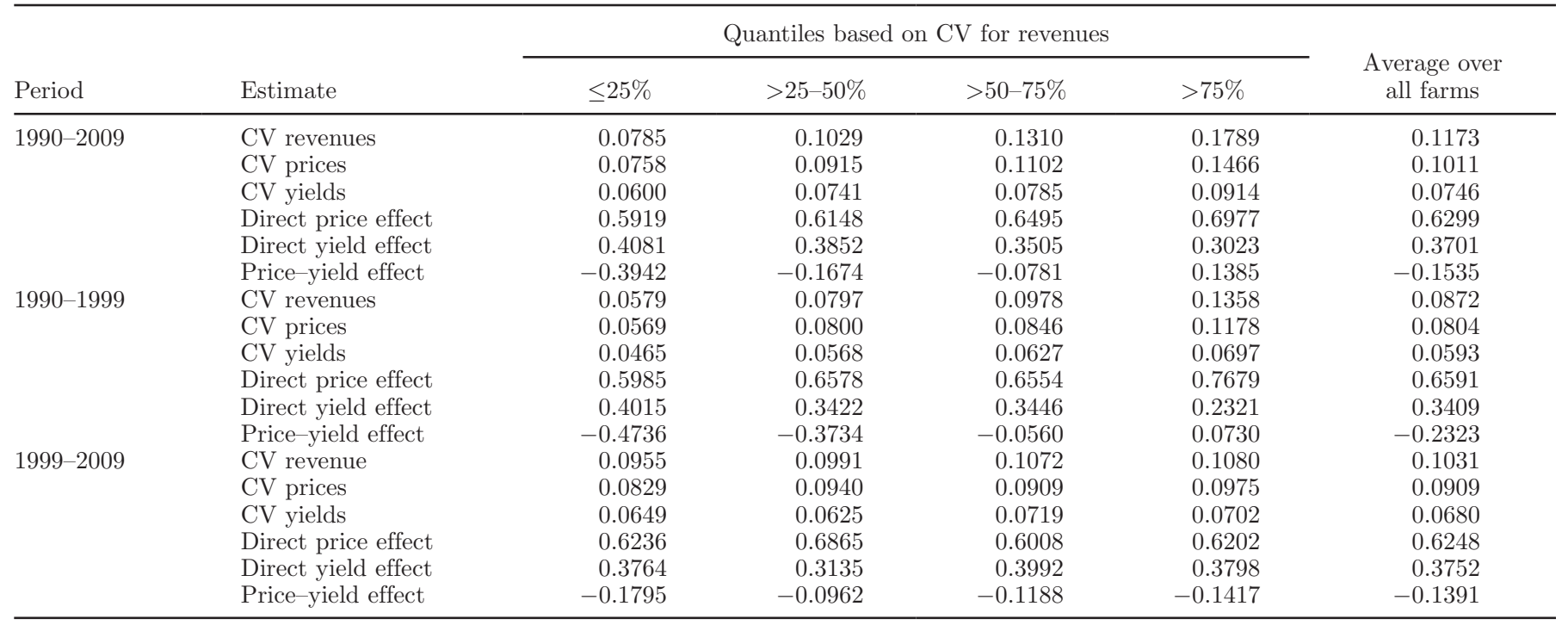

tion). In contrast, by totally abandoning the DP of 450 $\mathrm{CHF}$ and under current price variability, a farmer's CE would be reduced by $455 \mathrm{CHF}$; that is, from a $\mathrm{CE}$ of 4,397 to a CE of 3,942. Furthermore, abandoning DP in situations with an assumed milk price variability of 0.30 (bottom right corner of Figure 5) would decrease the CE by $487 \mathrm{CHF}$. Thus, with increasing price variability, the risk-reducing effect of DP increases. This is because the risk-reducing effect of direct payments is of higher utility for a risk-averse farmer in high-risk market environments.

The RP for the assumed combinations of direct payments and price variability are presented in Figure 6 . It shows that higher price variability increases and DP decrease the RP. For instance, going from the initial situation (black dot in Figure 6) to a milk price CV of 0.30 , the RP increases from about 49 to $329 \mathrm{CHF} /$ cow. Furthermore, increasing milk price CV increase

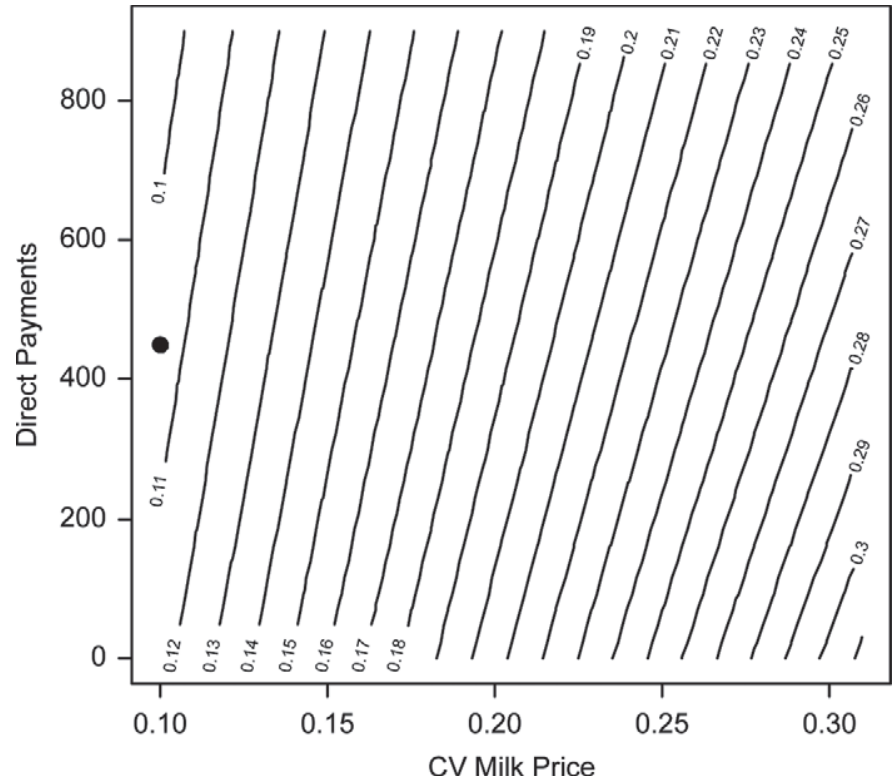

Figure 4. Sensitivity of the coefficients of variation (CV) of revenues to changing direct payments and milk price coefficients of variation (CV milk price). Black dot indicates initial situation.

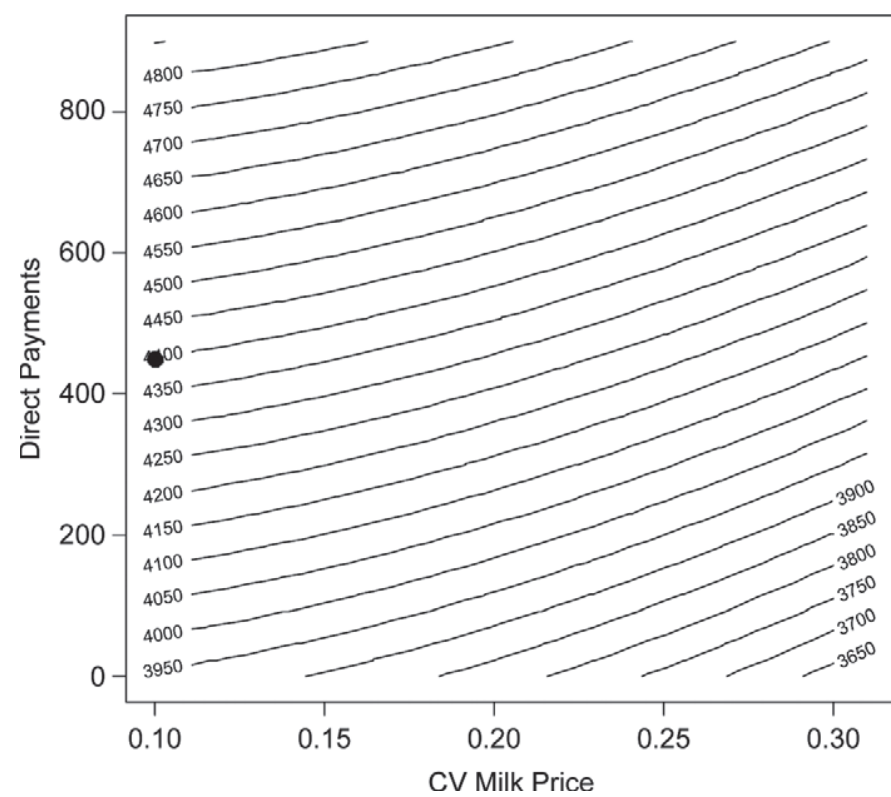

Figure 5. Sensitivity of the certainty equivalents to changing direct payments and milk price coefficients of variation (CV milk price). Black dot indicates initial situation. 


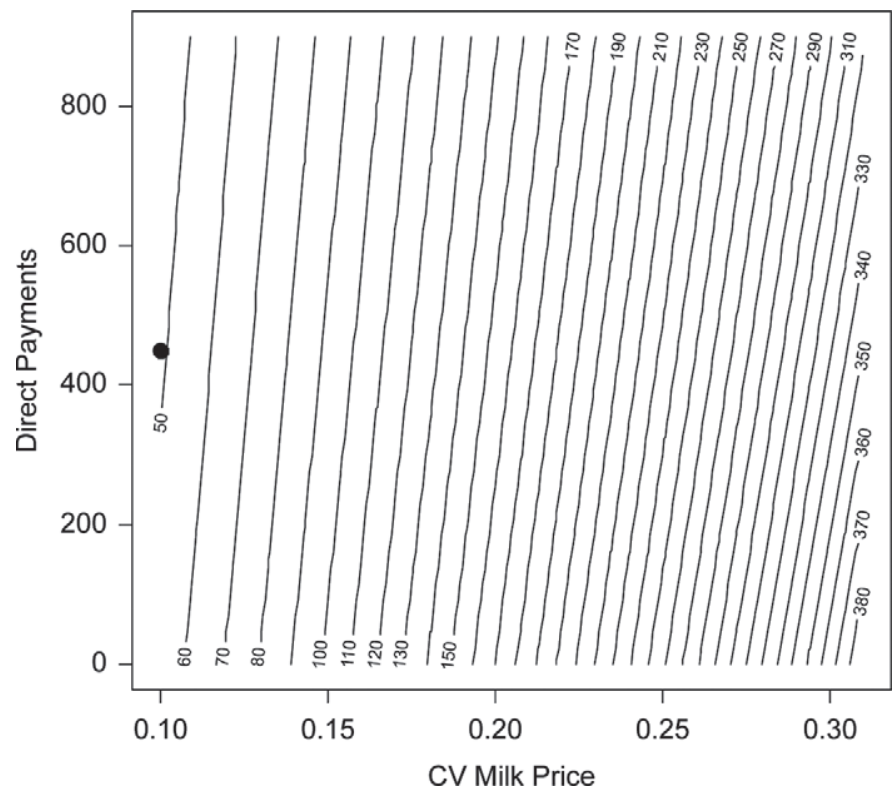

Figure 6. Sensitivity of risk premiums to changing direct payments and milk price coefficients of variation (CV milk price). Black dot indicates initial situation.

$\mathrm{RP}$ overproportionally, indicated by decreasing distances between the iso-CE lines. Figure 6 indicates that the willingness to remove revenue variability (i.e., the $\mathrm{RP}$ ) increases with a reduction in DP. For instance, the abolishment of DP under current price variability would increase the RP from $49 \mathrm{CHF}$ to $54 \mathrm{CHF}$ (i.e., by $5 \mathrm{CHF}$ ). However, if DP were abandoned in a situation in which price variability is 0.30 (i.e., the highest assumed price variability), the RP would increase from $329 \mathrm{CHF}$ to $366 \mathrm{CHF}$ and thus by an absolute amount of $37 \mathrm{CHF}$.

\section{CONCLUSIONS}

Price risk is the major source of revenue risk in Swiss dairy production, whereas production risk plays only a limited role. Furthermore, revenue risk is relatively low (with average CV of 0.12) compared with revenue risk of dairy producers in other countries (e.g., the United States) and with other farming activities in Switzerland (e.g., crop farming). This is due to low price and yield risks as well as to distinct negative correlations between prices and yields. However, we observed an increase of revenue risk over time, due to increases in both price and yield risk. Furthermore, the negative price-yield correlation decreased over time, showing the influence of market deregulation and market liberalization. Finally, the expected increase in price risk due to further market liberalization and deregulation and the abandonment of direct payments will lead to further increases of revenue risk in Swiss dairy production. As our analysis was based on the unit scale (i.e., a per-cow basis), this also indicates, ceteris paribus, a potential shift toward comparative disadvantages in terms of gross revenue risks compared with other farm activities. Depending on other available risk management strategies, market-based risk management instruments might be a valuable solution for Swiss dairy farmers if price risk increases in the future. However, further research should aim to investigate the role of changes in price and yield risks in a whole-farm perspective that also addresses the role of volatile fodder production and volatile cost levels.

\section{ACKNOWLEDGMENTS}

This work was supported by the Swiss Federal Office for Agriculture (Bern). We thank the Agroscope Reckenholz-Tänikon Research Station for providing the FADN data.

\section{REFERENCES}

Agrosynergie. 2011. Evaluation of income effects of direct support, Final Report 2011. European Community, Brussels, Belgium.

Bapst, B. 2001. Swiss experience on practical cattle breeding strategies for organic dairy herds. Pages 44-50 in Proc. 4th Network for Animal Health and Welfare in Organic Agriculture (NAHWOA) Workshop, Wageningen, the Netherlands. University of Reading, UK.

Berentsen, P. B. M., K. Kovacs, and M. A. P. M. van Asseldonk. 2012. Comparing risk in conventional and organic dairy farming in the Netherlands: An empirical analysis. J. Dairy Sci. 95:3803-3811.

Berentsen, P. B. M., and M. Tiessink. 2003. Potential effects of accumulating environmental policies on Dutch dairy farms. J. Dairy Sci. 86:1019-1028.

BLW. 2007. Jubiläumsschrift-125 Jahre Bundesamt für Landwirtschaft. Swiss Federal Office for Agriculture, Bern, Switzerland.

Bohrnstedt, G. W., and A. S. Goldberger. 1969. On the exact covariance of products of random variables. J. Am. Stat. Assoc. 64:1439-1442.

Bosch, D. J., and C. J. Johnson. 1992. An evaluation of risk management strategies for dairy farms. South. J. Agric. Econ. 24:173182.

Bötsch, M. 2004. Swiss agricultural policy and its focus on grassland. Pages 5-10 in Land Use Systems in Grassland Dominated Regions. Vol. 9. A. Lüscher, B. Jeangros, W. Kessler, O. Huguenin, M. Lobsiger, N. Millar, and D. Suter, ed. Hochschulverlage AG, ETH Zurich, Switzerland.

Burt, O. R., and R. M. Finley. 1968. Statistical analysis of identities in random variables. Am. J. Agric. Econ. 50:734-744.

Busato, A., P. Trachsel, M. Schällibaum, and J. W. Blum. 2000. Udder health and risk factors for subclinical mastitis in organic dairy farms in Switzerland. Prev. Vet. Med. 44:205-220.

Cafiero, C., F. Capitanio, A. Cioffi, and A. Coppola. 2007. Risk and crisis management in the reformed European agricultural policy. Can. J. Agric. Econ. 35:419-441.

Chavaz, J. 2010. Summary: The Swiss milk market. Panel of the High Level Experts Group on Milk, Brussels, Belgium. Deputy Director General, Federal Office for Agriculture, Bern, Switzerland.

Chen, G., N. C. Roberts, and C. S. Thraen. 2006. Managing dairy profit risk using weather derivatives. J. Agric. Res. Econ. 31:653666. 
Costa, C. N. 1999. An investigation into heterogeneity of variance for milk and fat yields of Holstein cows in Brazilian herd environments. Genet. Mol. Biol. 22:375-381.

Cross, J. A. 1994. Agroclimatic hazards and dairy farming in Wisconsin. Geogr. Rev. 84:277-289.

D'Antoni, J., and A. K. Mishra. 2012. Determinants of dairy farmers participation in the Milk Income Loss Contract program. J. Dairy Sci. 95:476-483.

Di Falco, S., and J.-P. Chavas. 2006. Crop genetic diversity, farm productivity and the management of environmental risk in rainfed agriculture. Eur. Rev. Agric. Econ. 33:289-314.

European Community. 2001. Risk Management Tools for EU Agriculture. Working Document of the European Commission EC. Agricultural Directorate-General of the European Community, Brussels, Belgium.

El Benni, N., and R. Finger. 2012. Where is the risk? Price, yield and cost risk in Swiss crop production. Pages 1-18 in Proc. 28th Triennial Conf. Int. Assoc. Agric. Econ. (IAAE), Foz do Iguaçu, Brazil. AgEconSearch: http://purl.umn.edu/126758.

El Benni, N., R. Finger, and S. Mann. 2012. Effects of agricultural policy reforms and farm characteristics on income risks in Swiss agriculture. Agric. Fin. Rev. 72:301-324.

El Benni, N., and B. Lehmann. 2010. Swiss agricultural policy reform: Landscape changes in consequence of national agricultural policy and international competition pressure. Pages 159-170 in Globalisation and Agricultural Landscapes - Change Patterns and Policy Trends in Developed Countries. J. Primdahl and S. Swaffield, ed. Cambridge University Press, Cambridge, UK.

Finger, R. 2010a. Evidence of slowing yield growth - The example of Swiss cereal yields. Food Policy 35:175-182.

Finger, R. 2010b. Revisiting the evaluation of robust regression techniques for crop yield data detrending. Am. J. Agric. Econ. 92:205-211.

Finger, R., P. Lazzarotto, and P. Calanca. 2010. Bioeconomic assessment of climate change impacts on managed grassland production. Agric. Syst. 103:666-674.

FMFACP. 2011. Risiko-und Krisenmanagement in der Landwirtschaft - Zur Rolle des Staates beim Umgang mit Ertrags- und Preisrisiken. Federal Ministry of Food, Agriculture and Consumer Protection, Bonn, Germany.

FOAG. 2000. Agrarbericht 2000 (Agricultural report 2000). Federal Office for Agriculture, Bern, Switzerland.

Gardebroek, C. 2006. Comparing risk attitudes of organic and nonorganic farmers with a Bayesian random coefficient model. Eur. Rev. Agric. Econ. 33:485-510.

Goodman, L. A. 1960. On the exact variance of products. J. Am. Stat. Assoc. 55:708-713.

Harwood, J., R. Heifner, K. Coble, J. Perry, and A. Somwaru. 1999. Management Risk in Farming: Concepts, Research, and Analysis. Agricultural Economics Report No. 774. US Department of Agriculture, Washington, DC.

Joerin, R., I. Schluep Campo, T. Maier, and C. Flury. 2006. Market liberalization and the role of direct payments in Switzerland. Pages 1-26 in Proc. Annu. Mtg. Japan. Assoc. Regional Agric. Forestry Econ. St. Andrew's University, Osaka, Japan.

Jeangros, B., and P. Thomet. 2004. Multi-functionality if grassland systems in Switzerland. Pages 11-23 in Land Use Systems in Grassland Dominated Regions. Vol. 9. A. Lüscher, B. Jeangros, W. Kessler, O. Huguenin, M. Lobsiger, N. Millar, and D. Suter, ed. Hochschulverlage AG, ETH Zurich, Switzerland.

Kadzere, C. T., M. R. Murphy, N. Silanikove, and E. Maltz. 2002. Heat stress in lactating dairy cows: A review. Livest. Prod. Sci. 77:59-91.

Lanz, S., L. Barth, and C. Hofer. 2010. Weiterentwicklung des Direktzahlungssystems. Agrarforschung Schweiz 1:10-17.

Li, Q., and J. S. Racine. 2007. Nonparametric Econometrics. Princeton University Press, Princeton, NJ.

Mann, S. 2003. Doing it the Swiss way. EuroChoices 2:32-35.

Mann, S., and M. Gairing. 2011. Post milk quota experiences in Switzerland. EuroChoices 10:16-21.
Mann, S., A. Zimmermann, A. Möhring, A. Ferjani, G. Mack, and S. Lanz. 2012. Welche Auswikrung hat di eUmlagerung der tierbezogenen Direktzahlungen? Agrarforschung Schweiz 3:284-291.

Martin, S. 1996. Risk management strategies in New Zealand agriculture and horticulture. Rev. Market. Agric. Econ. 64:31-44.

Maynard, L. J., C. Wolf, and M. Gearhardt. 2005. Can futures and option markets hold the milk price safety net? Policy conflicts and market failures in dairy hedging. Rev. Agric. Econ. 27:273-286.

McBride, W. D., and C. Greene. 2009. Characteristics, costs, and issues for organic dairy farming. Economic research report 82. US Department of Agriculture, Washington, DC.

Meuwissen, M. P. M., R. B. M. Huirne, and J. B. Hardaker. 1999 Income Insurance in European Agriculture. Scientific Report EU Project, European Economy, No. 2. Directorate General Economic and Financial Affairs (DGII), Brussels, Belgium.

Meuwissen, M. P. M., R. B. M. Huirne, and J. B. Hardaker. 2001. Risk and risk management: An empirical analysis of Dutch livestock farmers. Livest. Prod. Sci. 69:43-53.

Meuwissen, M. P. M., R. B. M. Huirne, and J. R. Skees. 2003. Income insurance in European agriculture. EuroChoices 2:12-17.

Perry, G. M., M. E. Rister, J. W. Richardson, and D. A. Bessler. 1989. Incorporating government program provisions into a meanvariance framework. South. J. Agric. Econ. 21:95-105.

Pratt, J. W. 1964. Risk aversion in the small and in the large. Econometrica 32:122-136.

Roesch, M., V. Perreten, M. G. Doherr, W. Schaeren, M. Schällibaum, and J. W. Blum. 2006. Comparison of antibiotic resistance of udder pathogens in dairy cows kept on organic and on conventional farms. J. Dairy Sci. 89:989-997.

Sato, K., P. C. Bartlett, R. J. Erskine, and J. B. Kaneene. 2005. A comparison of production and management between Wisconsin organic and dairy herds. Livest. Prod. Sci. 93:105-115.

Schaper, C., C. Wocken, K. Abeln, B. Lassen, S. Schierenbeck, A. Spiller, and L. Theuvsen. 2008. Risikomanagement in Milchviehbetrieben: Eine empirische Analyse vor dem Hintergrund der sich ändernden EU-Milchmarktpolitik. Landwirtschaftliche Rentenbank 23:134-184.

Schläpfer, F., M. Tucker, and I. Seidl. 2002. Returns from hay cultivation in fertilized low diversity and non-fertilized high diversity grassland. Environ. Res. Econ. 21:89-100.

Schmit, T. M., R. N. Boisvert, and L. W. Tauer. 2001. Measuring the financial risks of New York dairy producers. J. Dairy Sci 84:411-420.

Sckokai, P., and D. Moro. 2005. Modelling the Impact of the CAP Reform on Farm Investments. Pages 1-22 in Proc. XI EAAE Congress: The Future of Rural Europe in the Global AgriFood System, Copenhagen, Denmark. AgEconSearch: http://purl.umn. $\mathrm{edu} / 24468$

Stöcklin, J., A. Bosshard, G. Klaus, K. Rudmann-Maurer, and M. Fischer. 2007. Landnutzung und biologische Vielfalt in den Alpen, Synthesebericht Nationales Forschungsprogramm 48, Swiss National Science Foundation, vdf Hochschulverlag AG of ETH Zurich, Switzerland.

Thompson, S. R., and W. Gohout. 2000. CAP reform, wheat price instability and producer welfare. Pages 1-13 in Proc. Annu. Mtg. Am. Agric. Econ. Assoc., Tampa, FL. http://purl.umn.edu/21780.

Trachsel, P., A. Busato, and J. W. Blum. 2000. Body condition scores of dairy cattle in organic farming. J. Anim. Physiol. Anim. Nutr. (Berl.) 84:112-124.

Tyner, W. E., F. Jacquet, and A. W. Gray. 2005. Farm Income Stabilization: A Central Goal for American and European Policies. Pages 1-20 in Proc. XI EAAE Congress: The Future of Rural Europe in the Global AgriFood System, Copenhagen, Denmark. http://purl. umn.edu/24683.

Valvekar, M., J. P. Chavas, B. W. Gould, and V. E. Cabrera. 2011. Revenue risk management, risk aversion and the use of Livestock Gross Margin for dairy cattle insurance. Agric. Syst. 104:671-678.

van Winsen, F., E. Wauters, L. Lauwers, Y. de Mey, S. Van Passel, and M. Vancauteren. 2011. Increase in milk price volatility experiences by Flemish dairy farmers: A change in risk profile. Paper 
presented at the EAAE 2011 Congress: Change and Uncertainty, Challenges for Agriculture, Food and Natural Resources, Zurich, Switzerland. http://purl.umn.edu/115758

Wilson, P. N., T. R. Luginsland, and D. V. Armstrong. 1987. Risk perceptions and management responses of Arizona dairy producers. J. Dairy Sci. 71:545-551.

Wolf, C., J. R. Black, and J. Hadrich. 2006. Dairy farm revenue insurance: Is the application viable? Pages $1-20$ in Proc. Am. Ag- ric. Econ. Assoc. Annu. Mtg, Long Beach, CA. http://purl.umn. $\mathrm{edu} / 21286$.

Wolf, C. A., J. R. Black, and J. C. Hadrich. 2009. Upper Midwest dairy farm revenue variation and insurance implications. Agric. Fin. Rev. 69:346-358.

Yonkers, B. 2011. A Look at Dairy Market Price Volatility and Options for Dairy Policy Reform. International Dairy Foods Association, Washington, DC 